\title{
New uses for old drugs: Novel therapeutic options
}

\author{
U. Verma*, R. Sharma*, P. Gupta**, B. Kapoor*, G. Bano*, V. Sawhney
}

\author{
* Postgraduate Department of \\ Pharmacology and \\ Therapeutics, \\ Govt. Medical College, Jammu. \\ ** Department of ENT, \\ District Hospital Gandhi Nagar, \\ Jammu. \\ Received: 24.8.2004 \\ Revised: 18.11.2004 \\ Accepted: 10.1.2005 \\ Correspondence to: \\ Ujala Verma \\ E-mail : \\ ujala_verma@rediffmail.com
}

\begin{abstract}
Introducing a new drug to the market now costs an average of US\$ 897 million and is a time consuming process. Discovering new uses for the old drugs offers the advantage of providing time tested drugs for the benefit of the patients. Serendipity plays an important role in this. This therapeutic option may provide cost effective treatment, especially for the developing countries with limited resources. This article focuses on the new potential uses of some common drugs. However, these options need to be pursued by more researches so that the potential benefits could be passed on to the patients.
\end{abstract}

KEY WORDS: Non-label uses, potential uses, serendipity.
Since decades, the rational discovery of new medicines has depended on the modification of molecular structures. Introducing a new drug to the market now costs an average of US\$ 897 million which includes preclinical and clinical costs before the US FDA (Food and Drug Administration) approval and costs associated with studies conducted after a product has gained such approval. ${ }^{[1]}$ Moreover, the process of approval may take up to 15 years. The new drug may prove to be a loss in terms of its high manufacturing costs if it produces any unacceptable adverse reaction or toxicity in early years of marketing. In such prevailing conditions, discovering new uses for the already-existing time tested drugs with known adverse drug reaction profile may prove to be beneficial for the use of patients. Some older drugs have the potential and offer the advantage of extensive clinical experience in other therapeutic areas. They should be considered as potential partners to the products emerging from more recent research and development. Old drugs are resurfacing with new uses (but often off-label) as the underlying mechanism of diseases become understood. ${ }^{[2]}$ The American Medical Association (AMA) estimates that $40 \%$ to $60 \%$ of all prescriptions in the United States are written for unapproved/unlabelled purpose. An unapproved use merely indicates the lack of FDA approval and does not imply an improper or illegal use. Unlabeled use is a more appropriate term and is defined as the use of a drug product in doses, patient populations, routes of administration or for indications that are not included in FDA-approved product labeling. ${ }^{[3]}$ Many examples can be quoted to prove its benefits. For example, aspirin, approved by the FDA as a pain killer, was used to reduce the mortality rate among heart attack victims; the drug mitomycin, approved for the treatment of gastric and pancreatic cancers, has been found to be useful in the treatment of lung, bladder, breast and cervical cancers, as well as in certain forms of leukemia; trimethoprim, a drug approved to treat pneumonia, has been proved useful as an AIDS management. ${ }^{[4]}$ Moreover, discovering new uses for a new drug that does not work out for its intended use may be another aspect of utilizing the researches and is a valuable strategy because approximately $90 \%$ of experimental drugs in the industry fail. In fact, many pharmaceutical companies routinely follow this. The trials of experimental chemotherapy drug pemetrexed were halted following the death of some patients. However, now it is an approved treatment for mesothelioma and is under FDA consideration as a treatment for lung cancer. Pfizer Inc. originally developed the impotence drug sildenafil (viagra) to treat angina. Raloxifene, used for osteoporosis, was a failed contraceptive. Atomoxetine, now used for attentiondeficit/hyperactivity disorder failed as an antidepressant. ${ }^{[5]}$ The tenacious effort to develop new and specific agents to treat HIV infection is currently accompanied by a reconsideration of existing drugs on the basis of their known or putative effects on the retroviral life cycle and/or the tuning of immune mechanisms. ${ }^{[2]}$ Owing to the limitations with which the scientists can predict the efficacy in humans, medicines introduced for one disease state have subsequently been observed to be of value in unrelated diseases. ${ }^{[6]}$ In many instances, however serendipity plays an important role in the identification of such new uses for the old drugs. The accidental 
discovery of the ability of the antihelminthic drug disulfiram to produce toxic breakdown products during the metabolism of ethanol, led to its use in the treatment of chronic alcoholism. Similarly the anticonvulsant property possessed by potential antipsychotic drug carbamazepine became apparent on administering it to a patient of epilepsy suffering from behavioral pathology. ${ }^{|7|}$ Few examples of additional uses of drugs discovered during clinical usage are shown in [Table 1].

\section{Table 1}

Additional use of drugs discovered during clinical usage

\begin{tabular}{|c|c|c|}
\hline Drug & Initial use & $\begin{array}{c}\text { Additional or new } \\
\text { primary use }\end{array}$ \\
\hline Allopurinol & Antineoplastic & Treatment of gout \\
\hline Amantadine & Antiviral & Antiparkinsonism \\
\hline Amphetamine & Stimulant & Hyperkinesis in children \\
\hline Atomoxetine & Antidepressant & $\begin{array}{l}\text { ADHD (attention deficit } \\
\text { hyperactivity disorder) }\end{array}$ \\
\hline Beta-blocker & $\begin{array}{l}\text { Antiarrhythmic/ } \\
\text { antianginal }\end{array}$ & Antihypertensive \\
\hline Chlordiazepoxide & Muscle relaxant & Tranquilizer \\
\hline Chloroquine & Antimalarial & Antirheumatic \\
\hline Chlorpromazine & Anthelmintic & Antischizophrenic \\
\hline Imipramine & Sedative & Antidepressant \\
\hline Lignocaine & Local anesthetic & Antiarrhythmic \\
\hline Metronidazole & Antitrichomonal & $\begin{array}{l}\text { Antibacterial (anaerobic } \\
\text { organisms) }\end{array}$ \\
\hline Estrogens & $\begin{array}{l}\text { Replacement } \\
\text { therapy }\end{array}$ & Contraception \\
\hline Pemetrexed & Mesothelioma & Lung cancer \\
\hline Penicillamine & $\begin{array}{l}\text { Copper chelating } \\
\text { agent }\end{array}$ & Antirheumatic \\
\hline Raloxifene & Contraceptive & Osteoporosis \\
\hline Sildenafil & Angina & Male erectile dysfunction \\
\hline
\end{tabular}

The new uses of the old drugs therefore may provide costeffective treatment, especially in developing countries with limited resources. In the present review, we are presenting the novel potential uses of drugs (in alphabetical order) that are approved by FDA for important clinical conditions.

\section{Angiotensin converting enzyme inhibitor (ACEI) and angiotensin receptor blocker (ARB) in migraine}

Studies have suggested that ACEI ${ }^{[8]}$ and ARB ${ }^{[9]}$ might be useful agents for migraine prophylaxis. A few studies have reported the effectiveness of lisinopril and candesartan cilexetil as prophylactic agents. Although the exact mechanism is unknown, the rationale behind the positive effect of lisinopril in migraine prophylaxis is that it decreases the effect of angiotensin II, which might be causing direct vasoconstriction, increased sympathetic discharge, as well as adrenergic medullary catecholamine release. In addition, by acting at $\mathrm{AT}_{1}$ receptor in brain, angiotensin-II modulates cerebrovascular flow, electrolyte homeostasis, autonomic pathways, and modulates both potassium channels and calcium activity in cells. Moreover, components of renin angiotensin system are present in peripheral tissues, including the eye, and may play a role in controlling aqueous humor production, retinal blood flow, or retinovascular disease. Angiotensin II receptors of the retinal vasculature may play a major role in the autoregulation of blood supply to the retina and optic nerve head. Topical ACEI has been shown to lower the intra ocular pressure in rabbits, monkeys, and humans. These may act by inhibiting breakdown of bradykinin, by promoting formation of endogenous prostaglandins, and by enhancing uveoscleral flow. Therefore, ACEI might be a useful pharmacological agent in the medical therapy of glaucoma. ${ }^{10]}$

\section{Anti-TNF- $\alpha$ (tumor necrosis factor-alpha) in dermatology [11], [12]}

Infliximab and etanercept, widely used in the treatment of Crohn's disease and rheumatoid arthritis, was recently shown to be effective in the treatment of psoriasis and psoriatic arthritis. Results of a number of research and clinical studies suggest a role of biological agents that is, etanercept, infliximab (antiTNF- $\alpha$ ), anakinra (IL-1 [interleukin] receptor antagonist), huOKT3r1 (Anti-CD3 antibody), and alefacept (interference with the CD2/LFA-3 pathway) in psoriatic arthritis. At present, etanercept has been approved for use in psoriatic arthritis. Etanercept has been reported to be useful in conditions like cicatricial pemphigoid, subcorneal pustular dermatosis, toxic epidermal necrolysis, and concurrent sweet syndrome and erythema nodosum. Anti TNF- $\alpha$ was used to treat diseases like Behcet disease, Sjogren syndrome, synovitis-acnepustulosis hyperostosis-osteomyelitis syndrome, and ankylosing spondylitis. Hidradenitis suppurativa might be added to the growing list of dermatological diseases that respond to anti TNF- $\alpha$ therapy.

\section{Beta-blockers in malaria[13]}

Hormones that regulate cardiovascular function were discovered to influence malarial infection. As a consequence, beta-blockers, which are safe, inexpensive, and are commonly prescribed drugs used worldwide to treat high blood pressure, are effective against the deadliest and most drug-resistant strain of malaria parasites. World wide, there has been a resurgence of malaria in recent years, due mainly to the parasite's growing resistance to drugs and the mosquito's acquired resistance to insecticides developed to control the spread of the disease. Blocking this blood-stage infection by preventing the entry of the $P$. falciparum parasite into the red blood cells provides the most direct way to control infection and quell the symptoms of malaria. G-proteins in the red blood cell were shown to be used by the parasite to enter the red blood cells. It has been shown that a G-protein subunit, called $\mathrm{G}_{\mathrm{s}}$, concentrates around the malaria parasite during infection of the red blood cell, and several laboratory models of malaria have demonstrated that blocking the $\mathrm{G}_{\mathrm{s}}$ signal resulted in decreased malarial infection. Two major $\mathrm{G}_{\mathrm{s}}$-associated receptors, the beta-adrenergic and the adenosine receptors, are known to be present in red blood cells. Stimulating these receptors with an agonist, increased the infection of $P$. falciparum, whereas beta-blockers, which are antagonists, 
prevented the $P$. falciparum parasite from entering the red blood cells. The use of beta-receptor antagonists, such as those already used to treat high blood pressure may provide new approaches for treating malaria. Because beta-blockers are directed against a host target, there is a low chance of rapid emergence of resistance to these drugs. Moreover, they may be used in combination therapy with existing drugs against parasite targets. This finding offers the opportunity to use wellcharacterized, inexpensive drugs for a new, much-needed application, and the impetus for the development of new betablockers and other drugs is to be tested for effectiveness against malaria.

\section{Budesonide in graft versus host disease (GVHD) ${ }^{[14]}$}

GVHD is a common complication of hematopoietic stem cell transplantation mainly targeting the oral and gastrointestinal tract (GIT) mucosa. Budesonide, a potent nonhalogenated corticosteroid, indicated for the treatment of asthma and GIT disorders, has a very low bioavailability on oral application. Moreover, it undergoes rapid inactivation by biotransformation in liver, resulting in low potency metabolites. Therefore, a very low risk of systemic side effects exists with the recommended dosage in GVHD. Results suggest that budesonide has a clinical advantage over other treatments for chronic oral GHVD. ${ }^{[14]}$ However, future studies to determine the mucosal application, topical/oral dosage, and its application in other oral mucosal disorders are warranted.

\section{Calcium channel blockers inhibit platelet activation}

Calcium channel blockers are widely used antihypertensive drugs. However, diltiazem hydrochloride, a benzothiazepine derivative calcium channel blocker, has been demonstrated to significantly inhibit platelet activation, probably as a consequence of reduction of platelet $\left[\mathrm{Ca}^{2+}\right]_{\mathrm{i}}$ Although the accurate mechanism of calcium influx is still unclear, inhibition of an increase of platelet $\left[\mathrm{Ca}^{2+}\right]_{i}$ by calcium antagonists may represent a striking approach to the prevention of platelet activation after coronary interventional procedures. However, future studies should include platelet-specific and efficient calcium antagonists to evaluate their use. ${ }^{[15]}$

\section{Cimetidine in human papilloma virus (HPV) ${ }^{[16]}$}

Cimetidine, a $\mathrm{H}_{2}$-receptor antagonist with immuno-modulating properties has been shown to reverse the acquired tolerance to dinitrochlorobenzene to increase mitogen-induced lymphocyte proliferation and to inhibit suppressor T-cell activity. Recently, it has been used successfully in the treatment of several forms of HPV infection, including plane, plantar, and common warts resistant to previous therapies. Cimetidine, given in a dose of $40 \mathrm{mg} / \mathrm{kg} /$ day in three divided doses in a patient of epidermodysplasia verruciformis, has been reported to produce prompt therapeutic response, allowing almost complete clearing of lesions after 3 months of therapy and without onset of new lesions.

\section{Cyclooxygenase-2 (Cox-2) inhibitors in retinopathy and in Alzheimer disease}

Cox-2 contributes markedly to preretinal neo-vascularization in ischemic retinopathies and this effect seems to be $\mathrm{PGE}_{2}-$ mediated mostly by the $\mathrm{EP}_{3}$ receptors (prostaglandin E receptor 3) implicating a new interaction through thrombospondin-1 (TSP-1) and CD36. Results suggest that nonselective cox-2 inhibitors could be used for the control of pathological vitreal neovascularization in ischemic proliferative retinopathy. More specifically, $\mathrm{EP}_{3}$ (and possibly $\mathrm{EP}_{2}$ ) antagonists may be more selective by sparing the potential, physiologically desirable effects of the various cox- 2 products. ${ }^{[17]}$

Moreover, nonsteroidal antiinflammatory drugs (NSAIDs) may influence inflammation by inhibiting cox-1 and cox-2 by activating peroxisome proliferator nuclear transcription factor$\mathrm{g}$, which is a negative regulator of macrophage activation.[18] In addition, cox-mediated oxidation is important in the calciumdependent glutamate-signaling pathway that involves $\mathrm{N}$ methyl-D-aspartate. Therefore, NSAIDs may be able to protect neurons directly by decreasing the cellular response to glutamate and they have the potential to reduce the risk of Alzheimer's disease in old patients who are using NSAIDs for any other condition. ${ }^{[19]}$ Another potential application is in cancer chemoprophylaxis of melanoma. ${ }^{[20]}$ Increased cox-2 expression in malignant melanoma cell lines has also been reported. In a case-control study among women, inverse association of NSAIDs and malignant melanoma was reported. In a hairless mouse model, celecoxib significantly lengthened the tumor latency period and reduced tumor multiplicity (UV induced). ${ }^{20]}$

\section{Cyclosporin A}

Cyclosporin, a known immunosuppressant, is presently being investigated for various clinical conditions. It is the first FDA-approved therapy for keratoconjunctivitis sicca directed against the inflammatory component of dry eye. ${ }^{21]}$

Its therapeutic role in asthma includes a reduction in histamine and prostaglandin $\mathrm{D}_{2}$ production by stimulated mast cells and a reduction in tissue eosinophilia, and late airflow obstruction after allergen challenge. Improvement in lung function with $48 \%$ fewer exacerbations were observed in a study where 12-weeks course of cyclosporin was given to patients with steroid-dependent asthma. However, it should be reserved for the steroid- dependent patients with refractory symptoms, receiving specialized care. ${ }^{\text {22] }}$

Cyclosporin blocks the activation of T cells, and hence reduces the ability of the HIV to invade the cell. Moreover, it also prevents proper HIV virion maturation, and so it is being investigated for use in AIDS. However, clinical studies have produced conflicting results in HIV-infected patients in relation to immunological and disease effects, and toxicity. Hence, further studies are warranted. ${ }^{[2]}$

\section{Filgrastim in pneumonia and sepsis ${ }^{[23]}$}

Filgrastim (g-met HuG-CSF; Amgen,Thousand Oaks, CA) can enhance both neutrophil production and function, as well as improve survival in a variety of animal models of pneumonia. Addition of filgrastim to a regimen of intravenous antibiotics has been hypothesized to reduce the rate of mortality in patients with pneumonia and sepsis. Several cytokines and growth factors, including granulocyte-colony stimulating factor (G-CSF), appear to have a key role in the host's attempts to restore systemic homeostasis in severe sepsis. The enhanced production of G-CSF in response to an infectious challenge is 
critical for recruiting and optimizing phagocytic activity at local sites, which are involved in the removal of offending pathogens. Conversely, the major systemic effects of G-CSF are both antiinflammatory and immunosuppressive and appear to be focused on the inhibition of the production and action of inflammatory cytokines, as well as in expanding the T-helper lymphocyte response that might eventually lead to the production of specific antibodies to neutralize microbial pathogenic factors. Therefore, it could prove to be a novel addition.

\section{Fluoroquinolones in tuberculosis}

The continuing increase in tuberculosis infection, as well as a rising prevalence of multidrug resistance TB worldwide, provides the stimulus for new antitubercular drug development. The fluoroquinolones (FQ) have been studied for their therapeutic potential in the management of tuberculosis. These bactericidal drugs, that inhibit DNA gyrase, are highly active against mycobacterium tuberculosis, including strains that are resistant to first line drugs. Moxifloxacin and gatifloxacin have potent in vitro activity against mycobacterium tuberculosis. Moxifloxacin having the greatest sterilizing activity, a relatively long $\mathrm{t}_{1 / 2}$ and high area under the time concentration curve may be an ideal antituberculous drug. It has been found that the combination of rifampicin, pyrazinamide, and moxifloxacin has substantially greater sterilizing activity compared to the standard regimen, again suggesting the possibility that the drug would permit considerable shortening of treatment. The EBA (early bactericidal activity) is midway between INH, the drug that has the most potent EBA of all known agents and rifampicin, the drug with the greatest sterilizing activity. ${ }^{[24]}$ Moxifloxacin has an activity similar to that of rifampin in human subjects with pulmonary tuberculosis. Therefore, moxifloxacin joins the small number of highly bactericidal antitubercular drugs and may contribute to the development of more effective regimens. ${ }^{[25]}$

\section{Inhaled furosemide in asthma}

Initial studies have suggested that inhaled furosemide may be as effective as bronchodilator. ${ }^{[26]}$ The exact mechanism involved is not clear.

\section{Gabapentin for pain [27]}

Approved by the FDA in 1993, gabapentin has a complex and multiple action mechanism. It promotes increased GABA effect on the central nervous system (CNS), decreases glutamate, and blocks neuronal sodium and calcium channels. It is considered as a safe anticonvulsant drug. Moreover, it has the potential to relieve neuropathic pain that is associated to the following mechanism-quantitative changes in inhibitory and excitatory neurotransmitters, changes in CNS synapses, (inhibitory synapses become excitatory, latent synapses are activated and thick fibers may synapse with thin fibers), decreasing pain through descending inhibitory mechanism, changes in sympathetic system etc. Gabapentin has been reported to lead to complete remission in patients with sacral perineural cyst-induced pain.

\section{Glucocorticoids (GC) in sepsis [28], [29]}

GCs, the most important immunosuppressant agents, are an established therapy for chronic inflammatory diseases, as well as in transplantation medicine. Although in acute inflammation, especially in sepsis/septic shock, use of high dose was abandoned after a series of negative clinical trials, there now seems to be a renewed rationale for GC. Recent evidence indicates that adrenocortical insufficiency may be more common in septic shock, and low dose hydrocortisone regimens have shown promising results in sepsis. Low-dose hydrocortisone therapy has a primarily antiinflammatory and immune balancing role, rather than an immunosuppressive role in acute sepsis. It leads to a significant decrease in the level of proinflammatory cytokines (IL-6 and 8), as well as antiinflammatory mediators (IL-10) and soluble TNF receptors with an increase in in vitro phagocytosis and the monocyteactivating cytokine (IL-12). Stress hormones were shown to enhance macrophage production of acute phase proteins, complement factors, macrophage migratory-inhibiting factor, and sialoadhesin. Moreover, GCs were shown to act synergistically with interferons to produce $\mathrm{Fc}$ receptors on human monocyte cell lines and peritoneal macrophages, which are correlated with increased phagocytosis. Therefore, a positive, acute effect of GC is exerted on the immune system. In addition, immunoenhancing effect of GCs is exerted on the immune system. However, to avoid rebound effects, low-dose hydrocortisone has to be tapered over days. Further study is needed to identify the correct individual dosage, timing, mode of administration (bolus or infusion), duration of treatment, assessment of necessity (and appropriate time points) for adrenocortical function testing, the concomitant use of mineralocorticoids, and the emerging role of adrenal androgens.

\section{Levamisole for head lice ${ }^{[30]}$}

Levamisole, a nicotinic receptor antagonist, effective in eradicating ascaris, trichostrongylus, and hookworm, has been shown to be effective against pediculosis, in a dose of $3.5 \mathrm{mg} /$ $\mathrm{kg}$ administered for 10 days. In view of the growing evidence that head lice are becoming resistant to common pediculocides, levamisole may come up as a new therapy.

\section{Lidocaine for asthma ${ }^{[22]}$}

Lidocaine has recently received attention as a therapeutic agent in steroid-dependent bronchial asthmawith promising results seen with nebulized lidocaine (40-160 mg, $4 \mathrm{x}$ a day).

\section{Magnesium sulphate for asthma and tocolysis}

Magnesium is the fourth most common cation in the human body. It activates numerous enzymes and plays an important role in regulating cell permeability and neuromuscular impulse transmission to the synapses. Magnesium sulphate, blocks calcium-mediated smooth-muscle contraction, resulting in bronchodilatation. ${ }^{[26]}$ Several clinical studies have shown intravenous magnesium sulphate to be effective in acute asthma. Although not recommended for routine use in acute asthma, intravenous magnesium sulphate therapy may be con- 
sidered in patients with severe asthma exacerbation, unresponsive to albuterol, ipratropium, and systemic corticosteroid therapy, and on the brink of respiratory failure. Typical dose is $25-50 \mathrm{mg} / \mathrm{kg}$ given as a bolus over $2 \mathrm{~min}$ (max $2 \mathrm{gm} /$ dose). It is generally well tolerated. Side effects include flushing, tachycardia, bradycardia, hypotension, and loss of deep tendon reflexes. Nebulized magnesium sulphate has been shown to have bronchodilatory effect comparable to albuterol, and may be additive to albuterol. However, more clinical trials are needed both in adults and children to explore the therapeutic efficacy of combining nebulized albuterol and nebulized magnesium sulphate in acute asthma, before it is recommended for routine use.

Tocolysis may be another potential use of magnesium. ${ }^{[31]}$ Although the basis of tocolytic action of magnesium still remains unknown, it has been proposed that it competes with calcium for entry into the muscle cells. It was suggested that it binds competitively with calcium-storage sites in the endoplasmic reticulum and thereby uncouples the activation of actin-myosin unit. It was proposed to be an inexpensive, short-term tocolytic agent.

\section{Menatetrenone ( $\mathrm{Vit} \mathrm{K}_{2}$ ) and bone formation ${ }^{[32]}$}

Menatetrenone may have an important role in activating osteoblasts and promoting bone calcification. Vit $\mathrm{K}_{2}$ is a cofactor for $\gamma$-cardoxylase, which catalyses the conversion of glutamic acid residues on osteocalcin to g-carboxyglutamic acid, synthesizing $\gamma$-carboxylated osteocalcin that can bind hydroxyapatite. Supplementation with Vit $\mathrm{K}_{2}$, which exerts a stimulatory effect on bone formation in vivo and in vitro, has been shown to prevent prednisolone-induced loss of bone mineral density of the lumbar spine. It has also been reported to effectively prevent the occurrence of new fractures and ameliorate osteopenia in subjects with osteoporosis. Moreover, it also inhibits bone resorption through increased osteoclast apoptosis and decreased osteoclast formation in in vitro studies.

\section{Methotrexate (MTX)}

MTX was first introduced in 1948 as an anticancer drug, but since the 1960s it has been used to treat psoriasis and other skin conditions. Low dose MTX, an antiinflammatory drug, is a well-established medication for rheumatoid arthritis and psoriasis. However, now, low-dose methotrexate has emerged as a new therapy for chronically active Crohn disease in patients who are dependent on glucocorticoid and intolerant to thiopurine. Low-dose MTX acts as an immune modulator (and lacks the cytotoxic or antiproliferative effects) ${ }^{[33]}$ by promoting the extracellular adenosine release via intracellular 5-aminoimidazole-4-carboxamide ribonucleotide (AICAR) accumulation. MTX polyglutamates, most potently inhibit conversion of AICAR to formyl-AICAR by the enzyme AICAR transformylase, thereby leading to AICAR accumulation, which then promotes adenosine release. It has been shown that the antiinflammatory effects of low dose MTX are mediated via binding of adenosine to four distinct adenosine receptors, mainly $\mathrm{A}_{2}$ on target cells. In stimulated neutrophils, occupation of adenosine receptors inhibit the oxidative burst, adhesion to endothelial cells, and production of the proinflammatory agents like leukotriene $\mathrm{B}_{4}\left(\mathrm{LTB}_{4}\right)$ and TNF- $\alpha$. In monocytes and macrophages, adenosine inhibits expression of TNF- $\alpha$, IL-6, and IL-8, while stimulating transcription of the antiinflammatory cytokines. The combination therapy of MTX and infliximab in Crohn's disease is currently under investigation. ${ }^{[33]}$ Recently, it has been shown to be successful in low dose for the treatment of palmoplantar pompholyx which is unresponsive to other treatments, ${ }^{[34]}$ and in the treatment of a subset of patients with patch/plaque mycosis fungoides resistant to other therapies. ${ }^{[35]}$ In addition, the steroid-sparing potential of MTX has also been recognized in patients with concomitant psoriatic arthritis and asthma. A 50\% reduction in prednisolone has been observed with MTX $15 \mathrm{mg} /$ week for 24 weeks. $^{[22]}$

\section{Metronidazole in dermatitis ${ }^{[36]}$}

Various studies have shown that metronidazole, an imidazole-derived antibacterial and antiprotozoal agent, reduces oxidative tissue injury by inhibiting neutrophilgenerated inflammatory mediators- reactive oxygen species. The inhibitory effects of metronidazole are enhanced by palmitoleic acid, a free fatty acid found in human skin. It has immunomodulatory effects on leukocyte chemotaxis and selectively suppresses the cell-mediated immunity and has been found to be effective in the treatment of mild to moderate seborrheic dermatitis, a common skin disorder that affects persons of all ages.

\section{Nitrogen mustard for alopecia areata [37], [38]}

Topical nitrogen mustard (mechlorethamine), an alkylating agent, has been used in dermatology for several decades in the treatment of mycosis fungoides, histiocystis $\mathrm{x}$, multicentric reticulohistiocytosis, and psoriasis. It has been found to be beneficial in patients with alopecia areata. The mechanism of the action of mechlorethamine in alopecia areata is likely related to an immunomodulator effect on T-cells. A contact dermatitis similar to that which is caused by topical immunogens such as diphencyprone or squaric acid dibutyl ester may be the mechanism of action in inducing hair growth. However, a specific cytotoxic effect on pathogenic infiltrating T-cells in alopecia areata may be another mechanism of action. Mechlorethamine, as an alkylating agent, has the potential to be immunosuppressive and can alter the perifollicular immunologic milieu. Topical mechlorethamine may have the potential to become a more mainstream treatment of alopecia areata. However, more specifically targeted treatment approaches need to be designed.

\section{Octreotide for dumping syndrome ${ }^{[39]}$}

In the past decade, it has been suggested that octreotide an analogue of stomatostatin, can alleviate dumping by slowing gastric emptying, inhibiting insulin release, decreasing enteric peptic secretion, increasing intestinal absorption of water and sodium, slowing monosaccharide absorption, increasing gut transit time, and preventing hemodynamic changes. In particular, it has been demonstrated to be effective in patients refractory to standard therapy. Administration of octreotide 30 min before, or immediately after a meal offers a practical and effective approach to the treatment of early and late dumping syndrome. 


\section{Paclitaxel for preventing restenosis ${ }^{[40]}$}

The taxanes are potent antiproliferative agents used in cancer chemotherapy. They promote polymerization of the alpha and beta subunits of tubulin by reversibly and specifically binding the beta subunit of tubulin and thereby stabilizes the microtubules. In randomized controlled trials, stents coated with paclitaxel (paclitaxel-eluting stents; taxol coated stents) has been found to significantly reduce the binary restenosis rates after coronary angioplasty.

\section{Retinoids for AIDS related Kaposi sarcoma[4]}

Retinoids have antiproliferative, differentiating, apoptotic effects with moderate antitumor activity. All-trans-retinoic acid has significant activity in the treatment of acute promyelocytic leukemia and is capable of inducing complete hematologic and cytogenetic remissions. Oral alitretinoin, a natural panagonist for all-6-retinoic acid and retinoid X-receptors, has shown moderate activity against AIDS-related Kaposi sarcoma.

\section{Sirolimus (Rapamycin, Rapamune) as antitumor agent}

Sirolimus ${ }^{[42],[43]}$, a macrolide fungicide isolated from bacteria streptomyces hydroscopicus, approved by the US FDA for the prevention of allograft rejection after organ transplantation, has revealed significant antitumor activity. Now, this novel molecule is being investigated for therapeutic uses in various malignancies.

Activation of mammalian target of rapamycin (mTOR , 290$\mathrm{kDa}$ kinase), which is a PI3K- related kinase, in response to growth signaling through PI3K /AKT (a down stream effector of PI3K) pathway results in increased translation of several critical cell-cycle regulatory mRNAs, and has been shown to promote heart growth in transgenic mice. Its cellular mechanism is mediated by binding to FK506 binding protein. Rapamycin by blockade of mTOR function inhibits the PI3K/ AKT-mediated proliferative signals and restricts the proliferation of smooth-muscle cells by blocking cell-cycle progression at the $\mathrm{G}_{1} / \mathrm{S}$ transition. Several analogues of rapamycin have been selected for further development as anticancer agents. ${ }^{[41]}$ Rapamycin effectively attenuates hypertrophy of cultured myocytes induced by several growth factors, as well as load-induced cardiac hypertrophy, and this was associated with attenuation of the increase in myocyte cell size without causing lethality, loss of body weight, or deterioration of cardiac function. Moreover, rapamycin inhibits angiotensin II and phenylephrine-mediated hypertrophy of cardiac myocytes in vitro, and inhibition of S6K1 (p70 ribosomal S6 kinase 1- S6K1) has been implicated as a key factor in this response. ${ }^{[4]}$

Recently, it has been shown that rapamycin-coated stents potently inhibited restenosis after coronary angioplasty. Because rapamycin has a unique mechanism of action that is distinct from calcineurin inhibitors and is associated with less nephrotoxicity, rapamycin or its derivatives might be a useful modality to suppress cardiac hypertrophy, and could contribute to the control of arterial re-narrowing after percutaneous intervention ${ }^{[40]}$ due to antiproliferative and antimigratory activity.

\section{Statins in osteoporosis ${ }^{[44]}$}

HMGCoA reductase inhibitors are another class of drugs investigated for their potential role in osteoporosis. Statins like lovastatin and simvastatin have demonstrated increase in bone volume and rate of bone formation after oral therapy.

\section{Tetracyclines for osteoarthritis}

Tetracyclines were shown to inhibit phospholipase $A_{2}$, and thereby the production of lipooxygenase and cyclooxygenase derivatives. They are also shown to decrease proinflammatory mediators like nitric oxide and oxygen radicals, upregulate the production of inhibitors of matrix metalloproteinases, and decrease erythrocyte sedimentation rate and $\mathrm{C}$ reactive protein levels. Tetracyclines have also been shown to impair the proliferation and activation of human lymphocytes and synovial tissue cells with the resulting abrogation of the local production of proinflammatory cytokines. Tetracycline like minocycline has been established as DMARD for rheumatoid arthritis. The use of tetracyclines for the treatment of osteoarthritis is also under trial. ${ }^{[45}$ Owing to the discovery of (i) the surprising ability of the tetracycline antibiotics to inhibit mammalian tissuedestructive proteinases (collagenase, gelatinase) during a variety of disease processes, for instance, periodontitis, the arthritides, osteopenia/osteoporosis, sterile corneal ulcers, tumor invasion/metastasis/angiogenesis, and (ii) a series of chemically-modified, non-antibacterial analogs of tetracyclines to inhibit these enzymes without producing typical antibiotic side effects, tetracyclines have the potential for broader applications. ${ }^{[46]}$

\section{Thalidomide and its derivatives}

Thalidomide a derivative of glutaminic acid, was first clinically introduced in the 1950's as a sedative and subsequently withdrawn in 1961. In 1998, US FDA approved this drug for the treatment of erythema nodosum leprosum. Currently, it is under evaluation for the treatment of several disorders such as sarcoidosis, aphthous ulcers of HIV and Behcet disease, and chronic GVHD. More recently, it has shown encouraging results in plasma cell disorders (especially end stage myeloma), Kaposi's sarcoma, and certain solid tumors. ${ }^{[47]}$ It is categorized as an immunomodulatory agent with antiangiogenic and antiinflammatory properties. This, along with the observation that bone marrow angiogenesis is increased in myeloma, led to its use in patients with refractory end-stage myeloma. Multiple properties of thalidomide may explain its antimyeloma activity. It can induce $\mathrm{G}_{1}$ growth arrest and apoptosis, and down regulate TNF- $\alpha$ (possible growth factor for myeloma cells). Thalidomide treatment may decrease the expression of adhesion molecules on myeloma and marrow stromal cells (lymphocyte function-associated antigen-1, intercellular adhesion molecule-1 and vascular cell adhesion molecule-1) resulting in inhibition of myeloma cell adhesion and TNF- $\alpha$ stimulated interleukin (IL)-6 secretion. Moreover, it can block the activation of nuclear factor- $\kappa$ through a mechanism involving the inhibition of IkB kinase (regulatory protein) activity. It may increase antimyeloma immunity by promoting growth of already stimulated natural killer cells and T lymphocytes. Some, or all of these mechanisms may be clini- 
Table 2

\section{New potential uses of drugs}

\begin{tabular}{|c|c|}
\hline Drugs & Potential uses \\
\hline Lisinopril & Migraine prophylaxis ${ }^{8}$, glaucoma ${ }^{10}$ \\
\hline Candesartan cilexetil & Migraine prophylaxis ${ }^{9}$ \\
\hline Anti TNF- $\alpha$ therapy & Dermatology $y^{11,12}$, hidradenitis suppurativa ${ }^{11}$ \\
\hline Beta blockers & Malaria $^{13}$ \\
\hline Budesonide & GVHD $^{14}$ (Graft versus host disease) \\
\hline Diltiazem & Inhibition of platelet activation ${ }^{15}$ \\
\hline Cimetidine & HPV ${ }^{16}$ (Human papilloma virus) \\
\hline Cox-2 inhibitors & $\begin{array}{l}\text { Retinopathy }{ }^{17}, \text { Alzheimer's disease }{ }^{19} \\
\text { chemoprophylaxis of melanoma }{ }^{20}\end{array}$ \\
\hline Cyclosporin A & Asthma ${ }^{22}$, AIDS $^{2}$ \\
\hline Filgrastim & Sepsis ${ }^{23}$ \\
\hline Fluoroquinolones & Tuberculosis $^{24,25}$ \\
\hline Inhaled furosemide & Asthma ${ }^{26}$ \\
\hline Gabapentin & Pain $^{27}$ \\
\hline Glucocorticoids & Sepsis $^{28,29}$ \\
\hline Levamisole & Pediculosis ${ }^{30}$ \\
\hline Nebulized lidocaine & Asthma $^{22}$ \\
\hline Magnesium sulphate & Asthma $^{26}$, tocolysis $^{31}$ \\
\hline Menatetrenone & Osteoporosis ${ }^{32}$ \\
\hline Methotrexate & 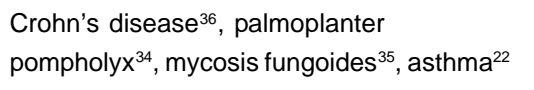 \\
\hline Metronidazole & Seborrheic dermatitis ${ }^{36}$ \\
\hline Nitrogen mustard & Alopecia $\operatorname{areata}^{37,38}$ \\
\hline Octreotide & Dumping syndrome ${ }^{39}$ \\
\hline Paclitaxel & Prevention of restenosis ${ }^{40}$ \\
\hline Retinoids & AIDS-related kaposi sarcoma ${ }^{41}$ \\
\hline Sirolimus & $\begin{array}{l}\text { Anticancer }{ }^{42}, \text { cardiac hypertrophy }^{43} \text {, } \\
\text { prevention of restenosis }{ }^{40}\end{array}$ \\
\hline Statins & Osteoporosis $^{44}$ \\
\hline Tetracyclines & Osteoarthritis ${ }^{45}$ \\
\hline Thalidomide & $\begin{array}{l}\text { Plasma cell disorders }{ }^{47} \text {, myeloma }{ }^{48}, \text { Crohn's } \\
\text { disease }{ }^{49} \text {, chronic discoid lupus } \\
\text { erythematosis }^{50} \text {, complex regional pain } \\
\text { syndrome }^{51} \text {, heart failure }{ }^{52} \text {, AIDS-related } \\
\text { conditions }^{2}\end{array}$ \\
\hline Zileuton & Acne $^{53}$, respiratory syncytial virus infection ${ }^{54}$ \\
\hline
\end{tabular}

cally relevant to the activity of thalidomide in myeloma. ${ }^{[47], ~[48]}$ It has been suggested that thalidomide may be of clinical application in the short-term management of orofacial granulomatosus and oral manifestations of Crohn's disease. ${ }^{[99]}$ Low-dose thalidomide therapy is effective as an alternative choice in chronic discoid lupus erythematosus resistant to the usual treatment. ${ }^{[50]}$ Moreover, its role is also documented in reflex sympathetic dystrophy, better known as complex regional pain syndrome (CRPS). Inhibition of production of TNF- $\alpha$ and other cytokines, which directly depolarize $\mathrm{C}$ and $\mathrm{A}_{\mathrm{d}}$ afferent pain fibers or reduce their threshold for firing could be a pos- sible mechanism. Alternatively, they may contribute to the inflammatory features of the disorder. ${ }^{[51]}$ More recently, an excess of inflammatory cytokines (TNF- $\alpha$ ) has been found in advanced heart failure and implicated in the progression of the disease. Therefore, thalidomide or its derivatives may have a role in the management of advanced heart failure. ${ }^{[52]}$

Thalidomide may have antiretroviral effects as a result of its primarily inhibitory effects on the production of TNF- $\alpha$. It is also documented that TNF- $\alpha$ induces expression of HIV from chronically infected cell lines by stimulating a cellular transcription factor and blocking of TNF- $\alpha$-stimulated HIV replication by thalidomide has been shown in vitro and $e x$ vivo. Thalidomide has also been shown to have potential in treating some AIDS-related conditions (e.g., cachexia and aphthous oral, esophageal or genital ulcers). ${ }^{[2]}$

\section{Zileuton for acne and RSV}

Synthesis of $\mathrm{LTB}_{4}$ is mainly controlled by 5-lipoxygenase. Among the several diseases, hyperkeratotic inflammatory skin disorders especially psoriasis seem to respond to $\mathrm{LTB}_{4}$ inhibitors. Recently potential involvement of arachidonic acid pathway has been documented in the development of acne and provides logical support for use of LTB $_{4}$ inhibitors in acne treatment. $\mathrm{LTB}_{4}$ is a natural ligand for peroxisome proliferator activated receptor-gamma (PPAR- $\gamma$ ) that has been shown to regulate lipid and lipoprotein metabolism, inflammatory response, cell proliferation, differentiation and apoptosis of various cell types, including sebaceous gland cells. Zileuton, a 5-lipoxygenase inhibitor, used for asthma has recently been shown to be effective in the treatment of acne in a dose of 600 mg 4 times a day, for 4 months. ${ }^{[53]}$

Its role is also coming up in the treatment of airway obstruction after respiratory syncytial virus (RSV) infection. In an experimental study, administration of zileuton markedly reversed airway constriction, reduced the number of inflammatory cells in the lung, as well as prevented the associated weight loss. The mechanism by which inhibition of leukotriene reduces the degree of respiratory illness is not clear. There may be involvement of an alternative pathway based on proinflammatory effect of leukotrienes. ${ }^{[54]}$ Montelukast, a LT antagonist, used for treatment of asthma, is also being tried for the management of COPD (chronic obstructive airway disease). ${ }^{[55]}$

\section{Conclusion}

Although a large number of old drugs with new potential uses have been discussed here [Table 2], still the list cannot be claimed to be complete. With advancement in our knowledge in various fields of medical sciences, we can make use of these time-tested drugs in diverse areas of clinical practice. Pharmaceutical marketing practices and physician dissatisfaction with the currently available pharmacological treatment options may be the key factors that contribute to this prescribing trend of drugs for off-label (unapproved) indications. ${ }^{[56]}$ However, unethical promotion of the irrational use of drugs for economic benefits by the pharmaceutical companies needs to be curbed. Unethical promotion and/or dangerous misuse of drugs can prove to be a threat to medical ethics. There is a need to develop programs to restrict the use 
of drugs to specific evidence-based situations (by journals, seminars, CMEs etc) ${ }^{[56]}$ It is the prime duty of the clinicians to look for all available evidences before putting an old drug to new use. The Food, Drug and Cosmetic Act of 1938 which required manufacturers to submit a New Drug Application (NDA) to the FDA for its approval before granting permission to market a new drug, was subsequently amended in 1962 with the Kefauver-Harris drug amendment. This amendment established that drugs should show substantial evidence of efficacy before receiving NDA approval. ${ }^{[57]}$ However, the FDA needs to show more responsiveness to changing knowledge and increased willingness to reconsider indications and contraindications in the light of newer experience, such as the approval of new uses for old drugs. ${ }^{[58]}$ It is also important that off-label use of compounds be brought up- to-date with current FDA policies, and to emphasize the responsibility of the prescribing physician in the use of these compounds. ${ }^{[59]}$ Neverthless, these initial findings discussed here need to be pursued by more researches so that the potential benefits could be passed on to the patients.

\section{References}

1. Pharma Times News [homepage on the Internet]. Drug development tops $\$ 897$ million. [cited 2003 May 15]. Available from: http://www.ptwebcast.com

2. Ravot E, Lisziewicz J, Lori F. New uses for old drugs in HIV infection: the role of hydroxyurea, cyclosporin and thalidomide. Drugs 1999;58:953-63.

3. Kimberly J, La Pointe. Childrens Hospital of the Kings' Daughters Norfolk, Virginia, USA. Available from: http://www.dekker.com/servlet/product/DOI/ 101081EECP 120006328/authors/?t=a\#0.

4. Esposito S. Off-label prescribing of drugs call FDA role into question. Medical Sentinel 2002;7:24.

5. Alliance for human research. Alliance for human research Protection. Available from: http://www.ahrpspeaks/ahrpspeaks.html

6. Newbold BB. How medicines are discovered? In: Burley DM, Clarke JM, Lasagna L, editors. Pharmaceutical Medicine. $2^{\text {nd }}$ ed. London: Pub. Edward Arnold; 1993. p. 1-11.

7. Stitzel RE, McPhillips JJ. Transitions and progress in therapeutics. In: Craig CR, Stitzel RE, editors. Modern Pharmacology with Clinical Applications. $5^{\text {th }}$ ed. New York: Pub. Little, Brown and Company (Inc.); 1997. p. 85-91.

8. Scrader H, Stovner LJ, Helde G, Sand T, Bovim G. Prophylactic treatment of migraine with ACE inhibitor lisinopril: Randomised, placebo controlled cross over study. Br Med J 2001;322:19-22.

9. Tronvik E, Stovner LJ, Helde G, Sand T, Bovim G. Prophylactic treatment of migraine with an angiotensin II-receptor blocker: A randomized controlled trial. JAMA 2004;3:89-92.

10. Saxena R, Prakash J, Mathur P, Gupta SK. Pharmacotherapy of glaucoma. Indian J Pharmacol 2002;34:71-85.

11. Lebwohl B, Sapadin AN. Infliximab for the treatment of hidradinitis suppurativa. J Am Acad Dermatol 2003;49:275-6.

12. Pipitone N, Kingsley GH, Manzo A, Scott DL, Pitzalis C. Current concepts and new developments in the treatment of psoriatic arthritis. Rheumatology 2003:42:1138-48.

13. Beta blockers effective against malaria parasites. Available from: www.northwestern.edu/univ-relations/ media_relations/releases/2003_09/ malaria_text.html

14. Elad S, Or R, Garfunkel A, Shapira MY. Budesonide: A novel treatment for graft versus host disease. Oral Surg Oral Med Oral Pathol Oral Radiol Endod 2003; 95:3008-11.

15. Dai H, Chen J, Tao Q, Zhu J, Zhang F, Zheng L, et al. Effects of diltiazem on platelet activation and cytosolic calcium during percutaneous transluminal coronary angioplasty. Post grad Med J 2003;79:522-6.

16. Micali G, Nasca MR, Dall'Oglio F, Masumeci ML. Cimetidine therapy for epidermodysplasia verruciformis. J Am Acad Dermatol 2003;48:9-10.

17. Sennlaub F, Valamanesh F, Vazquez-Tello A, El- Asrar, Checchin D, Brault S et al. Cyclo oxygenase-2 in human and experimental ischaemic proliferative retinopathy. Circulation 2003:108:198-204.

18. Ricote M, Li AC, Willson TM, Kelly CJ, Glass CK. The peroxisome proliferator activated receptor-gamma is a negative regulator of macrophage activation. Nature 1998;391:79-82.

19. in t' Veld BA, Ruitenberg A, Hofman A, Launer LJ, van Duijn CM, Stijnen T, et al. Nonsteroidal antiinflammatory drugs and the risk of Alzheimer's disease. $\mathrm{N}$ Engl J Med 2001;345:1515-21.

20. Demierre MF, Nathanson L. Chemoprevention for melanoma: An unexplored strategy. J Clin Oncol 2003;21:158-65.

21. Pflugfelder SC. Anti inflammatory therapy for dry eye. Am J Ophthalmol 2004;137:337-42.

22. Deykin A, Israel E. Newer therapeutic agents for asthma. Dis Mon 1999;45:11744.

23. Root RK, Lodato RF, Patrick W, Cade JF, Fotheringham N, Milwee S, et al. Multicentre double blind, placebo controlled study of the use of filgrastim in patients hospitalized with pneumonia and severe sepsis. Crit Care Med 2003;31:367-73.

24. O'Brien RJ. Development of fluoroquinolones as firstline drugs for tuberculosis - at long last. Am J Respir Crit Care Med 2003;168:1266-8.

25. Gosling RD, Uiso LO, Sam NE, Bongard E, Kanduma EG, Nyindo M, et al. The bactericidal activity of moxifloxacin in patients with pulmonary tuberculosis. Am J Respir Crit Care Med 2003;168:1342-5.

26. Bahrainwala $\mathrm{AH}$. Medical treatment of acute asthma in the emergency department. Synopsis: A current survey of world literature in pediatrics (www:pedsynopsis.com). 2003;5:5-13.

27. Magalhaes E, Mascarenhas AM, Kraychete DC, Sakata RK. Gabapentine to treat sacral perineural cyst induced pain: Case Report. Brazilian J Anaesthesiol 2004; $54: 75-7$

28. Bornstein SR, Briegel J. A new role for glucocorticoids in septic shock: balancing the immune response. Am J Respir Crit Care Med 2003;167:485-6.

29. Keh D, Boehnke T, Weber-Cartens S, Schulz C, Ahlers O, Bercker S, et al. Immunologic and hemodynamic effects of low dose $\mathrm{HC}$ in septic shock: A double blind randomized placebo controlled cross over study. Am J Respir Crit Care Med 2003;167:512-20.

30. Namazi MR. Levamisole: A safe and economical weapon against pediculosis. Int J Dermatol 2001;40:292-4. Erratum in: Int J Dermatol 2001 Dec;40:794.

31. Zygmunt M, Heilmann L, Berg C, Wallwiener D, Grischke E, Munstedt K, et al. Local and systemic tolerability of magnesium sulphate for tocolysis. Eur J Obstet Gynaecol Reprod Biol 2003;107:168-75.

32. Yonemura K, Fukasawa H, Fiyigaki Y, Hishida A. Protective effect of vit K2 and D3 on prednisolone-induced loss of bone mineral density in the lumbar spine. Am J Kid Dis 2004;43:53-60.

33. Schroder O, Stein J. Low dose methotrexate in inflammatory bowel disease: Current status and future directions. Am J Gasteroenterol 2003;98:530-7.

34. Shaffrali FC, Clover GB, Messenger AG, Ggawkrodger DJ. Experience with low dose methotrexate for the treatment of eczema in the elderly. J Am Acad Dermatol 2003;48:417-9.

35. Zackheim HS, Kashani-Sabet M, McMillan A. Low dose methotrexate to treat mycosis fungoides: A retrospective study in 69 patients. J Am Acad Dermatol 2003:49:873-8.

36. Koca R, Altinyazar $C$, Esturk E. Is topical metronidazole effective in seborrheic dermatitis? A double blind study. Int J Dermatol 2003;42:632-5.

37. Bernardo O, Tang L, Lui H, Shapiro J. Topical nitrogen mustard in the treatment of alopecia areata: A bilateral comparison study. J Am Acad Dermatol 2003:49:291-4.

38. Arrazola JM, Sendagorta E, Harto A, Ledo A. Treatment of alopecia areata with topical nitrogen mustard. Int J Dermatol 1985;24:608-10.

39. Li-Ling J, Irving M. Therapeutic value of octreotide for patients with severe dumping syndrome: A review of randomized controlled trials. Postgrad Med J 2001;77:441-2.

40. Bhatia V, Bhatia R, Dhinsa S. Drug-eluting intra coronary stents: Have we got the magic bullet. J Postgrad Med 2003;49:291-6.

41. Aboulafia DM, Norris D, Henry D, Grossman RJ, Thommes J, Bundow D, et al. 9-cis-retinoic acid capsules in the treatment of AIDS-related Kaposi sarcoma: Results of a phase 2 multicenter clinical trial. Arch Dermatol 2003;139:178-86.

42. Sausville EA, Elsayed Y, Monga M, Kim G. Signal transduction-directed cancer treatments. Annu Rev Pharmacol Toxicol 2003;43:199-231.

43. Shioi T, McMullen JR, Tarnavski O, Converso K, Sherwood MC, Manning WJ, et al. Rapamycin attenuates load-induced cardiac hypertrophy in mice. Circulation 2003;107:1664-70. 
44. Vogel G. Cholesterol-lowering drugs may boost bones. Science 1999;286:18256.

45. Alarcon GS. Antibiotics. In: Hochberg MC, Silman AJ, Smolen JS, Weinblatt ME, Weisman MH, editors. Rheumatology $3^{\text {rd }}$ ed. Vol. 1. London: Pub. Mosby; 2003. p. 491-6.

46. Golub LM, Schuler EK, Gallagher BM. New therapeutic uses for an old family of drugs: travels of a dental researcher from the lab to the university's office of technology transfer and beyond. Technol Health Care1996;4:311-6.

47. Dimopoulos MA, Anagnostopoulos A, Weber D. Treatment of plasma cell dyscrasias with thalidomide and its derivatives. J Clin Oncol 2003;21:444454.

48. Cavenagh JD, Oakervee $\mathrm{H}$. Thalidomide in multiple myeloma: current status and future prospects. Br J Haematol 2003;120:18-26.

49. Hegarty A, Hodgson T, Porter S. Thalidomide for the treatment of recalcitrant oral Crohn's disease and orofacial granulomatosis. Oral Surg Oral Med Oral Pathol Oral Radiol Endod 2003;95:576-85.

50. Kyriakis KP, Kontochristopoulos GJ, Panteleos DN. Experience with low-dose thalidomide therapy in chronic discoid lupus erythematosus. Int $\mathrm{J}$ Dermatol 2000;39:218-22.

51. Schwartzman RJ, Chevlen E, Bengtson K. Thalidomide has activity in treating complex regional pain syndrome. Arch Intern Med 2003;163:1487-8.

52. Davey PP, Ashrafian $\mathrm{H}$. New therapies for heart failure: Is thalidomide the answer? Q J Med 2000;93:305-11.

53. Zouboulis CC, Nestoris S, Adler YD, Orth M, Orfanos CE, Picardo M, et al. A new concept for acne therapy: a pilot study with zileuton, an oral 5 -lipoxygenase inhibitor. Arch Dermatol 2003;139:668-70.

54. Welliver RC 2nd, Hintz KH, Glori M, Welliver RC Sr. Zileuton reduces respiratory illness and lung inflammation, during respiratory syncytial virus infection, in mice. J Infect Dis 2003;187:1773-9.

55. Rubinstein I, Kumar B, Schriever C. Long-term montelukast therapy in moderate to severe COPD-a preliminary observation. Respir Med 2004;98:134-8.

56. Mack A. Examination of the evidence for off-label use of gabapentin. J Manag Care Pharm 2003:9:559-68.

57. Stitzel RE, McPhillips JJ. Progress in therapeutics. In: Craig CR, Stitzel RE, editors. Modern Pharmacology with Clinical Applications. $6^{\text {th }}$ ed. Philadelphia: Lippincott Williams and Wilkins; 2004. p. 3-9.

58. Shanklin DR. Doctors, drugs and the FDA. J Reprod Med 1972;9:203-5.

59. [No authors listed] Unapproved uses of approved drugs: The physician, the package insert, and the Food and Drug Administration: Subject review. American Academy of Pediatrics Committee on Drugs. Pediatrics 1996;98:143-5.

\title{
NATIONAL SEMINAR ON VETERINARY PHARMACOLOGY IN POST-WTO ERA AND
}

\section{$5^{\text {th }}$ ANNUAL CONFERENCE OF INDIAN SOCIETY OF VETERINARY PHARMACOLOGY AND TOXICOLOGY}

\author{
Date $\quad 24-26^{\text {th }}$ November, 2005 \\ Venue : Madras Veterinary College, Tamilnadu Veterinary and \\ Animal Sciences Unversity Chennai-600 007.
}

\section{Contact:}

\section{Dr. L.N. MATHURAM}

Organising Secretary and Associate Professor and Head, Department of Veterinary Pharmacology and Toxicology,

Madras Veterinary College, Chennai-600 007.

E-mail: isvptmvc05@rediffmail.com; mathuram.kumar@gmail.com 